\title{
A Year of Online Classes Amid COVID-19 Pandemic: Advantages, Problems, and Suggestions of Economics Students at a Bangladeshi Public University
}

\author{
Musharrat Shabnam Shuchi ${ }^{1}$, Sayeda Chandra Tabassum ${ }^{1}$, MMK Toufique $^{2, *}$ \\ ${ }^{1}$ Department of Economics, United International University, Madani Avenue, Dhaka 1212, Bangladesh; \\ shabnam@eco.uiu.ac.bd; tabassum@eco.uiu.ac.bd \\ ${ }^{2}$ Department of Economics, Noakhali Science and Technology University, Noakhali 3814, Bangladesh; \\ *Correspondence: mokammel.eco@nstu.edu.bd
}

\begin{abstract}
Though there have been works highlighting the advantages and disadvantages of online learning, no study focused on university-level economics students. None of the studies explored students' opinions about improving the quality and effectiveness of online classes. Many used questionable samples, closed-ended questions, and all those researches were carried out at the beginning of online classes. In this paper, we overcome these limitations of earlier studies. Using a convenience sampling technique and open-ended questions, we collect data from 154 universitylevel economics students after being exposed to the online class for a year. Some advantages of online classes are: students can do classes from home without being exposed to health risks, easily accessible, flexible class schedule, students remained connected with the study, it saves costs, reduce the likelihood of semester loss, easy to understand, less stressful, and learning new technologies. Major problems from students' perspectives include network problems, difficulties in understanding the topic, unsuitable for mathematical courses, concentration problem, class not interactive, financial constraint, adverse health impacts, device issues, power outages, unfamiliarity with digital technology, internet problem, and unfixed class-schedule. Disadvantages outnumbered advantages. Students made several suggestions to improve the quality and effectiveness of online classes. Some of the vital suggestions are: using state-of-the-art digital tools, recording and uploading lectures, resolving internet issues, holding classes regularly, higher efforts to make the topics easier, resolving network issues, lowering class duration, institutional support, implementing a fixed class schedule, and introducing online evaluation system.
\end{abstract}

Keywords: COVID-19; online learning; pandemic; online education; Bangladesh; students' perceptions; higher education; distance learning; online classes

JEL Code: I18, I21, I23, I28

\section{Introduction}

\subsection{Context}

Bangladesh reported the first COVID-19 case on March 8, 2020, and as of May 22, 2021, there were 786,698 confirmed cases and 12,310 deaths (WHO, 2021). The Ministry of Education 
instructed the shutdown of educational institutions and evacuations of students' residence halls on March 17, 2020, and they have not opened yet as of May 23, 2021. The total duration of school and university closure has now exceeded 60 weeks at a stretch of more than a year. In total, around 40 million learners have been affected. Of them, 7.88\%, i.e., around 3 million students, are at the tertiary level with $59.47 \%$ male students and $40.53 \%$ female students (UNESCO, 2021).

There are forty-nine public and one hundred and seven private universities in Bangladesh (UGC, 2021). Some private universities commenced online classes in April 2020 (The Business News, 2020). In May 2020, the University Grants Commission (UGC) instructed all universities to commence academic activities online (Dhaka Tribune, 2020). Though public universities were not allowed to take final examinations, the UGC allowed private universities to hold online examinations. As a result, public universities are conducting classes without any final evaluations, and their students are still in the same semester they were more than a year ago.

\subsection{A Brief Review of Literature}

The inception of distance education dates back to the early 1700s, when clergymen were trained through correspondence (Adams and Olszewski-Kubilius, 2007). As gradually technological advancements such as radio, television, computer, internet, and today's electronic forums became available, distance education, especially, online learning became extremely popular (OlszewskiKubilius and Corwith, 2010). However, Olszewski-Kubilius and Corwith (2010) warned about the effectiveness and success of distance education. Several studies have identified that Online education, though convenient, inexpensive, technology-reliant, and useful, involves less social interaction, doubtful assessments, difficulties for instructors, and uneven technological costs (Kumar 2010). Following Fedynich (2013), online learning is easily accessible, easy to participate in, can offer a blended course. However, Fedynich (2013) identified inadequate computer literacy and poor internet facilities as obstacles. For successful online classes, the curriculum and the learning and teaching method should be modified. All stakeholders should understand the online learning styles and the environment (Lewis et al., 2015). To be flexible learners, students should be exposed to the heterogeneous learning experiences available (Zapalska and Brozik, 2006). Online students tend to possess a powerful visual and read-and-write learning style (Drago and Wagner 2004).

In the face of the COVID-19 pandemic, universities around the world have adopted online learning. However, they did not take up an identical approach. For example, Crawford et al. (2020) studied 20 countries, including 14 developing countries and six developed countries. In developing countries, some campuses are open, some universities are delivering education online, and some are closed with no option for online learning. However, in most developed nations, universities adopted online learning to avoid semester loss. The necessary technological infrastructure and the attitude of the teachers and students are absent in many developing countries. In a study of lowincome countries, David et al. (2020) cited mobile network problems and internet problems as significant impediments.

Most of the studies examining the challenges of online learning have focused on primary education. For instance, Putri et al. (2020) used a qualitative case study approach to diagnose the limitations of online learning in Indonesian primary schools. They reported three challenges that students face; namely, students cannot communicate and socialize like in the pre-pandemic era, 
are required to look at the screen for a longer time, and students with special education need now faced a more significant challenge. Putri et al. (2020) used semi-structured interview questions to collect data. The sample consists of 15 teachers and parents of two primary schools who lived in the same area. Rasmitadila et al. (2020) collected data from 67 teachers in primary schools through surveys and semi-structured interviews and focused on teachers' perceptions of online learning. Following their analysis, factors like the flexibility of curriculum, technological preparedness, and facilitating roles of all stakeholders, i.e., institutions, teachers, guardians, community, and government, are crucial for Indonesia's online learning. Clark et al. (2020), using administrative data from three middle schools in China and employing the difference-in-difference approach, analyzed the causal effects of online learning on student performance. They found that students receiving online lessons from schools performed better than students in schools not offering online education. Students having access to online lectures of high-quality external teachers did better than students with access to online materials of internal teachers. Students using computers did better than smartphone users. Rural and urban students did not differ in terms of the benefits of distance learning. Also, online learning benefitted the low-achievers the most, and its impact on achievers was insignificant.

Using both open-ended and closed-ended questions, Agung et al. (2020) collected data on 66 Indonesian college students about their participation, accessibility, materials and assignment delivery, and suitability of the online platform used. They reported accessibility as the major problem affecting online learning. The study suggested using friendlier online platforms to increase students' participation. Octaberlina and Muslimin (2020) conducted a descriptive mixedmethod survey. They gave 20 university students seven statements and asked them to give their opinion on a 4-point Likert scale. They asked two questions to five students that had Yes/No as answers. The study identified unfamiliarity with e-learning, internet speed, and physical strain as the three obstacles. Students stressed the importance of training before attending the actual class. Also, they preferred breaks during the class and lower-sized files.

Muthuprasad et al. (2020) investigated Agricultural Student's opinion about online learning through a survey of 307 students. They found that most students preferred online classes during the closure, used smartphones, and preferred recorded classes with quizzes after each class. Flexibility and convenience were two essential benefits of online classes, while on the contrary, broadband connectivity was the main challenge in rural areas. Also, since agricultural education is practical-oriented, a complete shift to online learning is not pragmatic, and hence, a hybrid model is likely to do better. Rafi et al. (2020) listed barriers and perceptions about online classes reported by 364 undergraduate students after ten weeks of online learning. The survey revealed that students preferred recorded classes over live classes, and around ninety percent of students favored a shorter duration of classes. Finally, Subedi et al. (2020) surveyed teachers and students of 13 nursing colleges of Nepal involved in online classes. Even though most students were using data pack and mobile phone for online classes, most of them described electricity and the internet as key problems.

Biswas et al. (2020) attempted to gauge university students' perception of mobile learning. They surveyed 416 undergraduate and postgraduate students of Bangladeshi universities. Using a 5point Likert scale ranging from 'Strongly Disagree' to 'Strongly Agree', the study found that students had a favorable view of mobile learning. Students think it will reduce the study gap during 
COVID-19. The study collected data just after introducing online classes and asked 15 questions about students' perceptions of mobile learning. Ramij and Sultana (2020) collected data on 409 students from 12 private universities and examined the readiness for online classes in Bangladesh. They used the five-point Likert scale to evaluate capture students' opinions on different socioeconomic and infrastructural situations. The findings revealed that significant obstacles identified by the students are the absence of technological infrastructure, expensive internet and its low speed, pecuniary difficulties of the family, and mental pressure. Al-Amin et al. (2021) used the convenience sampling technique and summarized students' opinions about 14 questions where the answer was given in the Yes/No format. They collected data on 844 students from different universities in Bangladesh. Their findings revealed that most students did not have a separate reading room, and many students did not have an internet connection. Students' problems during online classes are not easily understandable, inattentiveness, power disruption, not being regular in classes, and unstable internet connection. Also, almost half of the students considered online classes ineffective. Dutta and Smita (2020) examined the impact of the pandemic on tertiary education in Bangladesh using a semi-structured survey of 50 students. The questions were openended, and the interview was conducted via telephone. As to online education, the challenges mentioned include unavailability of devices, accessibility, speed and price of the internet, and problems related to online platforms used.

\subsection{Research Questions}

The purpose of the study was to delineate a comprehensive picture of a Bangladeshi public university's economics students' experience of online learning after a year of initiation of online education. In doing so, we address the following research questions:

1. With a year of experience with online learning at the university level, what are the advantages that economics students are enjoying?

2. What are the unaddressed disadvantages that university-level economics students face after a year of online learning?

3. What measures do the students think would improve the experience of online learning?

\subsection{Contribution}

As the literature review suggests, though there have been works highlighting the advantages and disadvantages of online learning, they suffer from several limitations. Our study contributes to the relevant field in the following ways:

a. To the best of our knowledge, no study has been done focusing on Economics students at the university level. However, since economics has both mathematical and nonmathematical courses, economics students' perceptions deserve separate treatment.

b. None of the studies report students' perceptions about improving the quality and effectiveness of online classes. Unlike other studies, in this paper, a whole subsection is devoted to students' views about the steps required to surmount the obstacles in online learning.

c. All the studies employed closed-ended questions, i.e., the researcher provided a set of questions. Each question had a set of answers from which students were asked to select the appropriate one, and sometimes the answers were given in the Likert Scale. Examples of such studies include Putri et al. (2020), Rasmitadila et al. (2020); Agung et al. (2020), Octoberlina and Muslimin (2020), Subedi et al. (2020), Rafi et al. (2020), Muthuprasad et al. (2021), Biswas et al. (2020), Ramij and Sultana (2020) and Al-Amin et al. (2021). Dutta 
and Smita (2020), though used open-ended question, collected information through a telephone interview. In contrast, we used open-ended questions to divulge students' perceptions, and respondents knew that their identity would not be revealed. More importantly, the information is about what the students think, not about what the researcher thinks about what the students think.

d. Many of the existing studies have a small sample (for example, Putri et al., 2020; Rasmitadila et al. 2020; Agung et al., 2020; Octoberlina and Muslimin 2020; Dutta and Smita 2020). We use a sample of 154 students, and hence ours is more reliable and representative.

e. The existent studies were done immediately after introducing online classes, whereas this study is done after a year of online classes. As a result, our study can bring out meaningful insights and provide a comprehensive picture.

\subsection{Organization of the Paper}

The remaining paper is organized as follows. Section 2 describes the materials and specifies the methods. Section 3 reports the results. Finally, section 4 provides a discussion of the findings.

\section{Materials and Methods}

\subsection{Design}

We follow Rapanta et al. (2020) and define 'online learning' as the learning provided and received using the internet. Also, we use 'online learning' and 'online classes' interchangeably. However, most studies gathered information through surveys with closed-end questions. In such surveys, the researcher specified students' advantages and disadvantages, not the students themselves. Besides, in such surveys, students were required to select the answer from a given set of answers. Consequently, closed-end questions can be incapable of portraying the actual scenario of the phenomenon. Therefore, we surveyed with open-ended questions. Also, the researchers did not have any lead about a student's identity, which is crucial in a conservative setting like Bangladesh, where freedom of expression is not usually the norm.

\subsection{Participants}

The participants are 154 full-time students of the Department of Economics at a public university in Bangladesh. The University adopted online learning in May 2020, and in April 2021, a year was completed with online learning in place. The survey made no distinction between undergraduate and graduate students. The participants had no prior experience in online learning. Study was approved by Department of Economics, Noakhali Science and Technology University, Bangladesh, on 05 April 2021 (the code number of the ethical approval: NSTU/ECO/Research/2021/Apr01). The blank form of the informed consent: https://docs.google.com/forms/d/e/1FAIpQLSfTIKlo2v5QTM1yBA33jyA5xuvZQL3B vyRjjp7vdcPCCbA3aQ/viewform

\subsection{Data Collection}

The data were collected from a student survey using the convenience sampling technique, conducted via Google Forms. This simple survey consisted of three multiple-choice questions (MCQ) and three open-ended questions. The MCQ questions asked: (a) if the students were staying with their families during the pandemic, (b) if they need to go out to attend online classes, and (c) about the type of device they were using for online classes. The three open-ended questions were 
designed to identify the advantages and disadvantages of online classes and recommendations for more effective online classes. Specifically, the questions were: (a) What are the advantages of online class? (b) What are the disadvantages of online classes? (c) What should be done to improve the quality of the online class and make it more effective?

To ensure that students answer the questions without any fear of retribution, no identifying information was collected. However, students were made aware that there was no way to trace the respondent, and they could mention unpleasant truths. This particular feature brought out an exhaustive list of benefits, problems, and recommendations for online classes and made the study stand out among similar studies in the field.

\subsection{Analysis}

We use simple frequency distribution tables to summarize students' perceptions about online classes. Each table reports the frequency and percent frequency of a particular advantage/disadvantage/suggestion mentioned by students. Additionally, the last column of each table shows the percent of students reporting a specific advantage/disadvantage/recommendation. Identical responses, collected via students' open-ended statements, were grouped. One hundred fifty-four students reported advantages 336 times, disadvantages 452 times, and made suggestions for improvements 331 times. Lastly, the tables were analyzed, and the results were described.

\section{Results}

154 students of the Department of Economics at a Bangladeshi Public University participated in the survey. The survey was administered in April 2021 using google Forms. 91.56\% of the respondents stated that they stayed with their families during the pandemic, while $8.44 \%$ stayed outside the family. $71.43 \%$ of the responders could join online classes from home, whereas $28.57 \%$ of students needed to go out to join online classes. $92.21 \%$ of students used mobile phones for online classes, while $7.79 \%$ used desktop computers. On average, a respondent reported 2.18 advantages, 2.93 disadvantages and made 2.15 suggestions.

\subsection{Advantages of Online Class}

Though 06 students found online classes having no advantages, 148 students reported one or multiple benefits associated with online classes. Table 1 presents the 15 most frequently reported advantages of the online class by the students. The most significant advantage of an online class for the students is that they can do it from home. Sixty-two respondents, i.e., $40.26 \%$ of the students, mentioned it as an advantage. Twenty-three of these respondents specifically emphasized the additional health benefits from social distancing by staying home during the COVID-19 pandemic.

Furthermore, $30.52 \%$ of students state that online class saves time, especially travel time. This benefit is followed by $17.53 \%$ of students reporting the flexibility that online class gives in terms of location, time, and situation. Twenty-five students (16.23\%) say that they can remain connected with the study because of online classes while the University is closed. Twenty students (12.99\%) state cost saving as one of the advantages of the online class. Interestingly, saving travel costs was mentioned 12 times, whereas saving housing costs was brought up twice. Nineteen respondents, $12.34 \%$ of the survey participants, said that courses are getting completed even though the University is closed. Hence, without online classes, they would have faced session jams. Sixteen 
students (10.39\% of respondents) expressed that they can concentrate better in the online class. The reason cited is that the real classroom environment is noisy, but such disturbances can be minimized in a virtual classroom. A similar number of students found online classes advantageous as they can record and replay the class. Eleven students $(7.14 \%)$ found the class schedule more convenient because of its flexibility. Many, ten students, i.e., 6.49\%, found the virtual class easier to understand. Some of them attribute this to visual presentation, slides, and other tools in the online class. At the same time, two of them opined that this benefit is realized only for theoretical courses.

The following four advantages occurred in the survey with an identical frequency of six $(03.89 \%)$. 1. Students can attend classes while doing something else. This flexibility has reduced student absenteeism. 2. When the University is open, many students must stay away from home in student dormitories or hostels. Students can now stay and spend time with their families. 3. Students are getting familiar with digital learning tools. 4. More materials can be covered quickly. As a result, courses are getting completed fast.

Table 1: Advantages of Online Class

\begin{tabular}{|l|l|l|l|}
\hline Advantage & Frequency & $\begin{array}{l}\text { Percent } \\
\text { Frequency }\end{array}$ & $\begin{array}{l}\text { Percent of Students } \\
\text { Reporting }\end{array}$ \\
\hline Doing classes from home & 62 & 18.45 & 40.26 \\
\hline Saves time & 47 & 13.99 & 30.52 \\
\hline Attending classes from anywhere/anytime & 27 & 08.04 & 17.53 \\
\hline Students remaining connected with the study & 25 & 07.44 & 16.23 \\
\hline Saves costs & 20 & 05.95 & 12.99 \\
\hline Reducing the likelihood of session jam & 19 & 05.65 & 12.34 \\
\hline Can concentrate better & 16 & 04.76 & 10.39 \\
\hline Classes can be recorded and replayed & 16 & 04.76 & 10.39 \\
\hline Convenient class schedule & 11 & 03.27 & 07.14 \\
\hline Easy to understand & 10 & 02.98 & 06.49 \\
\hline Less stressful & 09 & 02.68 & 05.84 \\
\hline Can attend classes while doing something else & 06 & 01.79 & 03.89 \\
\hline Can stay and spend time with family & 06 & 01.79 & 03.89 \\
\hline Learning new technologies & 06 & 01.79 & 03.89 \\
\hline Topics get completed fast & 06 & 01.79 & 03.89 \\
\hline Others & 56 & 16.67 & 36.36 \\
\hline Total & $\mathbf{3 3 6}$ & $\mathbf{1 0 0}$ & \\
\hline
\end{tabular}

$03.25 \%$ of the students (05 students) listed the longer duration of the class and their ability to attend classes while sick as two benefits of the virtual class. The following benefits were listed by 01.29\% of the students (02 students): 1. More time to study at home 2. A proper Q/A session 3. Online class does not require interaction with others. Additionally, a good number of benefits of online classes were reported by a single respondent. The list includes submitting assignments instead of appearing in quizzes or class tests, not getting exposed to outside pollution, reducing the monotony during the pandemic, and courses can be completed with only a cell phone, to list a few. 


\subsection{Disadvantages of Online Class}

As exhibited in table 2, for university students, the mobile network problem is the biggest obstacle to a satisfactory experience in the online class. $59.09 \%$ of the participants cited this as an issue. The next problem on the list is students facing difficulty grasping the material presented in class, which $36.36 \%$ of the participants indicated as an impediment. Some of the reasons mentioned are lack of hands-on experience, fast delivery of the lecture, not using boards, topics not explained sufficiently, and students not having books. Finally, as reported by $31.17 \%$ of students, the third major problem of an online class is that it is unsuitable for topics involving graphs and mathematics. Also, lab courses cannot be completed online.

$26.62 \%$ of students complained that they could not concentrate. The family atmosphere is not conducive, some classes are longer than usual, and it is challenging to remain focused after a particular time (usually 30-40 minutes). The next hindrance is that online classes are not interactive and participatory like actual classes. Some of the views in this regard are that there is no face-toface interaction, students cannot question as in the actual classroom, the environment is not lively, many do not or cannot participate, not as satisfactory as an actual class, etc.

Table 2: Problems of Online Class

\begin{tabular}{|l|l|l|l|}
\hline Problem & Frequency & $\begin{array}{l}\text { Percent } \\
\text { Frequency }\end{array}$ & $\begin{array}{l}\text { Percent of Students } \\
\text { Reporting }\end{array}$ \\
\hline Network problem & 91 & 20.13 & 59.09 \\
\hline Difficult to understand & 56 & 12.39 & 36.36 \\
\hline $\begin{array}{l}\text { Okay for theoretical courses but not for mathematical } \\
\text { courses }\end{array}$ & 48 & 10.62 & 31.17 \\
\hline Cannot concentrate & 41 & 09.07 & 26.62 \\
\hline Not interactive and participatory as a real classroom & 31 & 06.85 & 20.13 \\
\hline Financial constraint & 26 & 05.75 & 16.88 \\
\hline Health issues & 18 & 03.98 & 11.69 \\
\hline Device issues & 17 & 03.76 & 11.04 \\
\hline Power outage & 17 & 03.76 & 11.04 \\
\hline Unfamiliarity with digital technology & 17 & 03.76 & 11.04 \\
\hline Students are not sincere & 14 & 03.09 & 09.09 \\
\hline Internet problem & 14 & 03.09 & 09.09 \\
\hline Erratic and unsuitable class schedule & 11 & 02.43 & 07.14 \\
\hline Need to go out for class & 8 & 01.77 & 05.19 \\
\hline Cannot benefit from peers & 6 & 01.33 & 03.89 \\
\hline Classes not held regularly & 6 & 01.33 & 03.89 \\
\hline Others & 31 & 06.86 & 20.13 \\
\hline Total & $\mathbf{4 5 2}$ & $\mathbf{1 0 0}$ & \\
\hline
\end{tabular}

$16.88 \%$ of students mentioned financial constraints as an obstruction. Though some specifically mentioned that their families were facing pecuniary difficulties, the majority found the internet expensive. In addition, many students, $11.69 \%$ of the participants, raised concerns about various health-related issues. For example, it is difficult to look at the screen for a more extended period, and it causes a headache, eye irritation, back pain, and neck pain. Besides, some get addicted to the device or internet. 
$11.04 \%$ of students listed device issues, power outages, and unfamiliarity with digital technology as three obstacles they are facing. Students not having a proper device was recognized by the Government of Bangladesh at the beginning of the COVID-19 pandemic. Through the University Grants Commission (UGC), initiatives were undertaken to give students loans to purchase a device. Nineteen students of the Department of Economics initially applied for the loan, but later, when the preconditions of the loan were disclosed, only one student finally applied for it. Consequently, even after a year of the commencement of the online classes, the device-related problem remains. Electricity-related issues are something that cannot be resolved overnight. According to the survey, many instructors and students are not comfortable with the state-of-theart digital tools for online classes. An online lecture should be different from an actual lecture since the setting is entirely different.

$09.09 \%$ of students inform that many of them are not sincere about the online class. Some students get busy with something else while doing the class, and many do not regularly attend class. A similar number of students mention that the internet issue is causing a problem in the online class.

$07.14 \%$ mentioned that the class schedule is not fixed, and sometimes classes are held at an inconvenient time. $05.19 \%$ of students said they need to go outside the home to join the class as the network is not available at home. Many classes are held in the evening. Some students need to go out at night for these classes, which raises security issues, especially for female students. $03.89 \%$ of students said they could not benefit from peers as they cannot discuss or do group study with their classmates. An equal number of students stated that classes are not held regularly, which happens without prior notice.

Additionally, there were nine disadvantages, each of which was reported by two respondents, and there were 13 disadvantages, each having a single respondent. As reported, some are not studying much now, and students have no scope for socializing. Some believe that online classes are inefficacious without evaluation. A few expressed concern that the online class creates inequality between rural and urban students as infrastructure is better in the urban areas.

\subsection{Suggestions to Improve the Quality and the Effectiveness of Online Class}

Table 3 reports 15 notable suggestions made by students to improve the experience of the online class. The use of state-of-the-art digital tools tops the list of suggestions. It was proposed by $35.71 \%$ of the participating students. They suggested using tools like slides, whiteboard, digital pen, touchpad, tripod, screen sharing, google classroom, messenger groups, and apps. Almost half of them said that better use of digital technology would help them understand topics entailing graphs and mathematics. The survey also reveals that student experience would be improved if teachers use the same apps.

The second most prominent suggestion on the list is recording the lectures and uploading them on some platform to access the lectures whenever they want. This suggestion is followed by resolving issues related to internet facilities. Most of these respondents espoused special internet packages for all students at a zero or reduced price. The rest requested for ensuring a higher speed internet. 
The subsequent two suggestions on the table are to hold classes regularly and giving higher efforts to make materials easy to understand, with each being mentioned by $19.48 \%$ of students. Students suggest that there should be a routine and it should be followed strictly, i.e., taking at least two classes per week per course, which would help finish topics and hence, courses in time. Students also felt that there should be more significant efforts to make study materials easy to understand. This broad suggestion includes providing lecture notes and materials before class, explaining with examples, both teachers and students should come to the class prepared, slowing down the pace, giving time to copy, giving review classes, and reducing the syllabus.

Next came resolving the network-related issues that involve a considerable investment by both public and private sectors and cannot be solved quickly. $18.83 \%$ of students proposed this. $12.34 \%$ of students suggested reducing the duration of the class. According to the students, some classes are 3 hours long, which are difficult to concentrate. They suggested a class duration of 40-60 minutes. Also, some believe that topic-based classes will be better. A similar share of the students expects a more crucial supporting role from the institution. The specific suggestions that fall into this category are: giving stipend to necessitous students, providing teachers and students with all the required equipment, arranging training for faculty members, counseling sessions for students, and creating an online institutional platform.

Table 3: Suggestions for Improvement

\begin{tabular}{|l|l|l|l|}
\hline Suggestion & Frequency & $\begin{array}{l}\text { Percent } \\
\text { Frequency }\end{array}$ & $\begin{array}{l}\text { Percent of Students } \\
\text { Reporting }\end{array}$ \\
\hline Using state-of-the-art digital tools in class & 55 & 16.62 & 35.71 \\
\hline Recording classes and uploading online & 35 & 10.57 & 22.73 \\
\hline Resolving internet issues & 33 & 09.97 & 21.43 \\
\hline Holding classes regularly & 30 & 09.06 & 19.48 \\
\hline Higher efforts to make materials easy to understand & 30 & 09.06 & 19.48 \\
\hline Resolving network issues & 29 & 08.76 & 18.83 \\
\hline Reducing class duration & 19 & 05.74 & 12.34 \\
\hline Greater institutional support & 19 & 05.74 & 12.34 \\
\hline Resolving device-related problems & 18 & 05.44 & 11.69 \\
\hline Solving class schedule-related problems & 12 & 03.62 & 07.79 \\
\hline Online evaluation system & 10 & 03.02 & 06.49 \\
\hline Making the class more participatory & 10 & 03.02 & 06.49 \\
\hline Creating a student-friendly environment & 08 & 02.42 & 05.19 \\
\hline Better discipline in the class & 07 & 02.11 & 04.54 \\
\hline Addressing the issue of student inattentiveness & 04 & 01.21 & 02.59 \\
\hline Others & 14 & 04.23 & 09.09 \\
\hline Total & $\mathbf{3 3 1}$ & $\mathbf{1 0 0}$ & \\
\hline
\end{tabular}

$11.69 \%$ of students recommended solving device-related issues. In their opinion, all students, especially the poor ones, should be given a mobile phone at a reasonable price. Some suggested that the device should be given free of cost. Solving the problems related to class schedule, such as adhering to a fixed schedule and giving sufficient breaks between classes, were put forward by $07.79 \%$ of students.

$06.49 \%$ stated the need for an online evaluation system. Up to now, there has not been any evaluation of student performance except assignments. Students suggested not only taking quizzes 
or class tests online but also taking final exams online. A similar number of students say that making the class more participatory would help make the online class better. Some students also requested Q/A sessions which would make the class more participatory. This proposal was followed by the suggestion of creating a student-friendly environment. Students opined that their problems should be acknowledged and addressed in the class, they should be allowed to enter the class if late by 10 minutes, and they should be notified at least 24 hours before an unscheduled class is held.

$4.54 \%$ of students advocated for better discipline in the class. They suggested ensuring that students attend classes regularly, keeping and updating attendance records, and a strict late entry policy. Also, $02.59 \%$ of students suggested that teachers should address the issue of student inattentiveness. However, 06 students gave no suggestions. One of them said no solution to the problems, and one expressed facing no problem in online classes.

\section{Discussion}

The previous section described the results of the study, placing the findings in three broad categories, namely, advantages, disadvantages, and suggestions. In this section, we bring all those pieces together and discuss them briefly.

\subsection{Accessibility}

Online classes enable students to do classes from anywhere, especially from home. However, accessibility is marred by network problems. Though many students mentioned accessibility as an advantage, more students mentioned experiencing network or internet problems. However, a fewer number of students mentioned improving accessibility as a suggestion. This is probably because resolving countrywide network and internet problems are long-term issues and require huge investment.

\subsection{Flexibility}

According to the students, flexibility is another advantage of online classes. Online classes can be recorded and played anytime. Therefore, the class schedule is convenient, and students can attend classes while doing something else. However, an erratic class schedule was found to reducing flexibility to a certain extent. Therefore, many suggested that faculty members should record lectures, upload them on some online platform, and solve class-schedule-related problems. These suggestions will improve flexibility.

\subsection{Avoiding Semester Loss}

Students felt that they have been able to remain connected with the study because of online classes, reducing the likelihood of semester loss. Since online classes had started a year ago and the University, like other Bangladeshi public universities, has not taken any exams, some students felt that the classes are not very effective without exams, and many advocated for introducing an online evaluation system.

\subsection{Learning Environment}

Many students found the learning environment of online classes favorable. They were able to concentrate better, could grasp the materials quickly, and topics were getting completed faster. 
Notwithstanding, a more significant number of students expressed dissatisfaction about the learning environment in online classes. They found the class challenging to understand, especially when the topic was mathematical. The online class was not interactive and participatory like a real class, and students could not benefit from their classmates. Also, classes were not held regularly. There were a good number of suggestions specifically to improve the overall learning environment of an online class. These include more outstanding efforts of faculty members to make topics easily understandable, holding classes regularly, reducing the duration of lectures, creating a studentfriendly environment, enforcing better discipline in the class, making the class more participatory, and addressing student attentiveness.

\subsection{Financial Constraint}

Online classes save costs of transportation, boarding, and food. Nevertheless, some students faced financial constraints during the pandemic and could not buy a suitable device, i.e., a cellular phone. In addition, some found the mobile data package expensive. Students sought greater institutional support to resolve these issues.

\subsection{Health Issues}

Since students are attending classes from home, they are less exposed to the coronavirus and outside pollution. In addition, online classes are less stressful. They can spend more time with their families, which might positively impact their mental health status. In contrast, longer screen time has adverse health impacts. Reducing class duration can help in this regard.

\subsection{Infrastructure}

Power outages, network errors, and internet problems are three obstacles students face while doing online classes. Unfortunately, solving these issues requires investments in both the public and private sectors, and these problems can not be resolved readily.

\subsection{Digital tools}

Students are getting acquainted with new digital tools owing to online classes. However, many cited not being unfamiliar with digital tools as an obstacle. Following their suggestions, recording and uploading the lectures and using state-of-the-art digital tools will solve the problem.

\subsection{Limitations and Future Research}

A limitation of this study is that we did not interview the faculty members. Since, apart from the students, they are the essential stakeholders, their perceptions might have contributed to a complete evaluation of online classes. In addition, the faculty members are likely facing some of the students' constraints, i.e., network and inter problems, power outages, device problems, and health issues that have impacted the students' experience with online learning. Thus, future research should explore both the students' and teachers' perspectives simultaneously.

Funding: This research received no funding.

Conflicts of Interest: The authors declare no conflict of interest.

\section{References}


Adams, C.M. \& Olszewski-Kubilius, P. (2007). Distance learning and gifted students. In J. VanTassel-Baska (Ed.). Serving gifted learners beyond the traditional classroom: A guide to alternative programs and services. Waco, TX: Prufrock Press, pp. 169-188.

Al-Amin, Md., Zubayer, A.A., Deb, B. \& Hasan, M. (2021). Status of tertiary level online class in Bangladesh: students' response on preparedness, participation and classroom activities. Heliyon, 7(1), e05943. https://doi.org/10.1016/j.heliyon.2021.e05943

Agung, A.S.S.N., Surtikanti, M.W. and Quinones, C.A. (2020), "Students' perception of online learning during COVID-19 pandemic: a case study on the English students of STKIP PamaneTalino", Journal of Social Sciences and Humanities, Vol. 10 No. 2, pp. 225-235.

BANBEIS. (2018). Summary Statistics and Key Performance Indicators (KPI). Retrieved from BANBEIS: https://data.banbeis.gov.bd/images/ban222.pdf

Biswas, B., Roy, S. K., \& Roy, F. (2020). Students Perception of Mobile Learning during COVID-19 in Bangladesh: University Student Perspective. Aquademia, 4(2), ep20023. https://doi.org/10.29333/aquademia/8443

Clark, A. E., Nong, H., Zhu, H., \& Zhu, R. (2020). Compensating for Academic Loss: Online Learning and Student Performance during the COVID-19 Pandemic.

Crawford, J., Butler-Henderson, K., Rudolph, J., Malkawi, B., Glowatz, M., Burton, R., Magni, P., \& Lam, S. (2020). COVID-19: 20 countries' higher education intraperiod digital pedagogy responses. Journal of Applied Learning \& Teaching, 3(1), 1-20.

David, R., Pellini, A., Jordan, K. \& Phillips, T. (2020), Education during the COVID-19 crisis Opportunities and constraints of using EdTech in low-income countries, Policy brief, April 2020, Retrieved from https://edtechhub.org/wp-content/uploads/2020/04/education-during-covid-19-crisis.pdf

Drago, W. and Wagner, R. (2004), "Vark preferred learning styles and online education", Management Research News, Vol. 27 No. 7, pp. 1-13. https://doi.org/10.1108/01409170410784211

S. Dutta, M. K. Smita, "The Impact of COVID-19 Pandemic on Tertiary Education in Bangladesh: Students' Perspectives," Open Journal of Social Sciences, vol. 8, no. 9, pp. 53-68, 2020.

Fedynich, L. V. (2013). Teaching beyond the classroom walls: The pros and cons of cyber learning. Journal of Instructional Pedagogies, 13.

Kumar, D. (2010). Pros and cons of online Education. Manuscript, North Carolina State University, Raleigh, NC, USA.

Lewis, S., Whiteside, A. and Dikkers, A. (2015), "Providing Chances for Students to Recover Credit: Is Online Learning a Solution?", Exploring Pedagogies for Diverse Learners Online (Advances in Research on Teaching, Vol. 25), Emerald Group Publishing Limited, pp. 143-157. https://doi.org/10.1108/S1479-368720150000027007

Muthuprasad, T.; Aiswarya, S.; Aditya, K.; Jha, G.K. Students' perception and preference for online education in India during COVID -19 pandemic. Soc. Sci. Humanit. Open 2021, 3, 100101.

Octaberlina, L. R., \& Muslimin, A. I. (2020). Efl students perspective towards online learning barriers and alternatives using moodle/google classroom during covid-19 pandemic. International Journal of Higher Education, 9(6), 1-9.

Olszewski-Kubilius, P., \& Corwith, S. (2010). Distance education: Where it started and where it stands for gifted children and their educators. Gifted Child Today, 34(3), 16-24, 64-65. doi:10.1177/107621751103400306 
Putri, R., Purwanto, A., Pramono, R., Asbari, M., Wijayanti, L., \& Hyun, C. (2020). Impact of the COVID19 pandemic on online home learning: An explorative study of primary schools in Indonesia. International Journal of Advanced Science and Technology, 29(5), 4809-4818.

Rafi AM, Varghese PR, Kuttichira P (2020) The pedagogical shift during COVID 19 pandemic: online medical education, barriers and perceptions in Central Kerala. J Med Educ Curric Dev 7:1-4

Ramij, M. and Sultana, A. (2020), "Preparedness of online classes in developing countries amid COVID-19 outbreak: a perspective from Bangladesh", SSRN Electronic Journal, available at: https://doi. org/10.2139/ssrn.3638718

Rapanta C., Botturi L., Goodyear P., Guàrdia L., Koole M. Online university teaching during and after the covid-19 crisis: refocusing teacher presence and learning activity. Postdigital Sci. Edu. 2020;2:923-945.

Rasmitadila R., Aliyyah R.R., Rachmadtullah R., Samsudin A., Syaodih E., Nurtanto M. The perceptions of primary school teachers of online learning during the COVID-19 pandemic period: A case study in Indonesia. Journal of Ethnic and Cultural Studies. 2020;7(2):90. doi: 10.29333/ejecs/388.

Subedi, S., Nayaju, S., Subedi, S., Shah, S. K., Shah, J. M. (2020). Impact of e-learning during COVID-19 pandemic among nursing students and teachers of Nepal. International Journal of Science and Healthcare Research, 5(3), 9.

UGC (2021). https://ugc.portal.gov.bd/ . Accessed May 232021.

UNESCO (2021). COVID-19 Educational Disruption and

https://en.unesco.org/covid19/educationresponse. Accessed May 202021.

WHO (2021). Bangladesh: WHO Coronavirus (COVID-19) Disease Dashboard. https://covid19.who.int/region/searo/country/bd . Accessed May 232021.

Zapalska, A. and Brozik, D. (2006), "Learning styles and online education", Campus-Wide Information Systems, Vol. 23 No. 5, pp. 325-335. https://doi.org/10.1108/10650740610714080 